\title{
Alice Krieg-Planque, «Purification ethnique» - Une formule et son histoire
}

\section{Rachele Raus}

\section{(2) OpenEdition}

1 Journals

\section{Édition électronique}

URL : http://journals.openedition.org/studifrancesi/33968

DOI : 10.4000/studifrancesi.33968

ISSN : 2421-5856

Éditeur

Rosenberg \& Sellier

\section{Édition imprimée}

Date de publication : 1 décembre 2005

Pagination : 699-700

ISSN : 0039-2944

\section{Référence électronique}

Rachele Raus, «Alice Krieg-Planque, «Purification ethnique» - Une formule et son histoire », Studi

Francesi [En ligne], 147 (XLX | III) | 2005, mis en ligne le 30 novembre 2015, consulté le 18 avril 2021.

URL : http://journals.openedition.org/studifrancesi/33968 ; DOI : https://doi.org/10.4000/

studifrancesi.33968

Ce document a été généré automatiquement le 18 avril 2021.

\section{(c)}

Studi Francesi è distribuita con Licenza Creative Commons Attribuzione - Non commerciale - Non opere derivate 4.0 Internazionale. 


\title{
Alice Krieg-Planque, «Purification ethnique» - Une formule et son histoire
}

\author{
Rachele Raus
}

\section{RÉFÉRENCE}

ALICE KRIEG-PLANQUE, «Purification ethnique» - Une formule et son histoire, Paris, CNRS, 2003, $523 \mathrm{pp}$.

1 Dans ce livre Alice KRIEG-PLANQUE analyse le parcours de la formule «purification ethnique» qui a été utilisée en France pendant le conflit en ex Yougoslavie. L'A. définit les formules comme «des séquences qui revêtent un caractère problématique, autrement dit qui suscitent des questions et des réponses» (pp. 305-306).

Dans le premier chapitre, il est question de retracer les cinq événements «mondains», c'est-à-dire réels, qui ont fournit le substrat historique à la formule dont il est question. Un deuxième chapitre est dédié aux «lieux discursifs», à savoir aux textes, aux mots d'ordre et aux désignants qui forment autour de la formule un interdiscours renvoyant aux positionnements des acteurs sociaux du conflit (chapitre 3). Il s'agit, pour ce qui est des textes, du Mémorandum de l'Académie des sciences et des arts de Belgrade, de la Déclaration d'Alija Izebegovic et de la Déroute de Franjo Tudjman; pour ce qui est de mots d'ordre, des formules qui ont un caractère déontologique comme par exemple «Plus jamais ça»; pour ce qui concerne les désignants, de mots comme «M/musulman», «belligérant»...

Les deux derniers chapitres, qui constituent la deuxième partie de l'ouvrage, renvoient directement à l'utilisation de la formule en contexte. Dans le quatrième chapitre l'A. présente les trois proto-formules (nettoyage / épuration / purification + ethnique) et les variantes qu'on retrouve dans les textes avant l'utilisation définitive de la formule «purification ethnique» en 1994. L'approche quantitative permet de retracer les différents moments de l'évolution des usages de la formule ainsi que leur relation aux événements mondains. Le dernier chapitre montre les étapes de la genèse et de la mise 
en circulation de la formule par rapport aux acteurs sociaux et à la polémique que l'utilisation de la formule déchaîne. La relation aux acteurs et leurs positionnements émergent de l'analyse des non-coïncidences du dit (voir Jacqueline Authier-Revuz, Ces mots qui ne vont pas de soi, Paris, Larousse, 1995), «à savoir: non-coïncidence interlocutive, non-coïncidence du discours à lui-même, non-coïncidence entre les mots et les choses, non-coïncidence des mots à eux-mêmes» (p. 306).

L'apparition et l'évolution de la formule, ainsi que les polémiques qu'elle entraîne dans l'espace public, sont toujours mises en rapport avec le contexte historique et social. Cela dit, des aspects plus nettement linguistiques sont également présents: l'analyse et l'utilisation de la formule en tant que nom propre ou bien comme nom commun; l'aspect prototypique et sémantique de la formule et de ses variantes; l'observation des «paradigmes définitionnels», pour reprendre l'expression de Mortureux ( $L a$ lexicologie entre langue et discours, Paris, Sedes, 1997); les définitions de la formule dans les dictionnaires...

5 A travers ce parcours diachronique, l'A. nous restitue de manière ponctuelle les enjeux et les évolutions d'une formule qui donc s'avère être un «terme de relation», à savoir «un terme qui établit une relation d'intelligibilité entre les faits qui adviennent dans l'espace yougoslave et les acteurs de l'espace public français» (p. 305). 